Jarosław Płuciennik, Michał Wróblewski

\author{
HASSREDE UND REDEFREIHEIT \\ EIN KONZEPTUELLER KULTURWISSENSCHAFTLICHER \\ UND ANTHROPOLOGISCHER RAHMEN ${ }^{1}$
}

\title{
1. Einführung
}

Der „Hate“ (poln. hejt2) ist generell ein neuer Terminus, jedoch basierend auf dem gesunden Menschenverstand erscheint die Assoziation mit dem etymologisch herzuleitenden Begriff des Hasses am einfachsten. Über Liebe und Hass ist in der Literatur und Kultur viel geschrieben worden, insbesondere in anthropologischen Kontexten. Das Böse erörterte man auch aus der ethologischen Perspektive, menschliches Verhalten wurde oft auch im Kontext der Verhaltensweisen von Tieren erörtert (vgl. etwa Lorenz 1963; poln. Ausgabe 1972). Wenn über Hass geschrieben wurde, schrieb man oft über die Philosophie des Menschen und der Kultur, wobei Hass in einen breiteren Kontext von Aggression, Missgunst und Neid sowie mimetischer Verhaltensweisen eingebunden wurde (vgl. die weite Konzeption von Rene Girard 1987). Es ist merkwürdig, dass es heutzutage an theoretisch starken Konzeptionen des Bösen und der menschlichen Aggression mangelt, sodass es auch schwer fällt, einen konzeptuellen Rahmen für die Theorie des Hates zu finden. Eine Ausnahme in dieser Hinsicht bildet die Konzeption von Pinker, die er in seinem Buch Zmierzch przemocy. Lepsza strona naszej natury (The Better Angels of Our Nature) (2015) zum Ausdruck bringt. Laut dieser Auffassung wird das Ausmaß der Aggression, der Gewalt und des Bösen in dem Prozess der Zivilisierung der Menschheit trotz der medialen

\footnotetext{
1 Aus dem Polnischen übersetzt von Jacek Makowski. Sprachliche Beratung und Korrektur von Heinrich Hofmann-Psuty.

2 Für die im vorliegenden Beitrag verwendeten polnischsprachigen und in der Schreibung an das Polnische angepassten Bezeichnungen hejt, hejter, hejtować und hejterstwo wurden für die deutschsprachige Fassung die Pendants Hate, Hater, haten und Haterei gewählt. Die ausgangssprachliche Bezeichnung wird dabei jeweils bei Erstnennung in Klammern nachgestellt - Anm. des Übersetzers.
} 
Omnipräsenz dieser Erscheinungen immer geringer. Der Autor führt konkrete Statistiken, Berechnungen und Proportionen an und argumentiert auf der Basis von Zahlenangaben. Dabei bezieht er sich nicht auf symbolische Gewalt, die als mit dem Zivilisierungsprozess assoziiert erscheinen mag, wovon die im Buch Nadzorować i karać. Narodziny więzienia (dt. Überwachen und Strafen: Die Geburt des Gefängnisses) (2009) ausgezeichnet ausgedrückte Konzeption von Michel Foucault zeugte. Pinker ist eindeutig ein anthropologischer Optimist, Foucault hingegen ein Pessimist. Unter den von uns erörterten theoretisierenden Herangehensweisen an das Hate-Phänomen finden wir keine ausdrucksvollen anthropologischen Thesen. Die jungen Forscher meiden breite philosophische oder anthropologische Rahmen; ihre Analysen charakterisiert dafür eine interessante, zu denken gebende Auswahl von Kontexten und Methodologien sowie eine bestimmte Applikabilität und Pragmatizität.

\section{Case Study}

Versuchen wir die Frage des sog. Hates und Hassrede im breitestmöglichen Kontext zu betrachten. Im Hauptteil des Beitrags präsentieren wir einen Überblick über die von den Vertretern der polnischen ,jungen“ $\mathrm{Hu}$ manistik sowie der Sozial- und Rechtswissenschaften erörterte Thematik, kritische Strömungen und methodologische Diskurse, die zugleich an die Problematik der Kommunikation im Netz und der vernetzten Gesellschaft anknüpfen. Unser Ziel ist es, dem deutschsprachigen Adressaten die neuesten wissenschaftlichen Reflexionen im Hinblick auf das Phänomen der „Haterei“ (poln. hejterstwo) näher zu bringen. Die vorliegend dargestellte Rekapitulation der von polnischen Wissenschaftlern der jüngsten Generation geführten Forschungsarbeiten entstand in Anlehnung an Beiträge, die in der von dem Verlag der Universität Łódź veröffentlichten Monographie Hejterstwo - nowa praktyka kulturowa? Geneza, przypadki, diagnozy (dt. Haterei - eine neue kulturelle Praxis? Genese, Fälle, Diagnosen) (Hejterstwo 2017) enthalten sind.

Das Buch ist das Ergebnis einer bekannt gewordenen, landesweiten Fachtagung, in deren Verlauf unter anderem über die Genese, Erscheinungsräume und -formen der „Hates“, der Erscheinung des Hates in Literatur und Kultur sowie dem sozialpolitischen Erscheinungsbild des Haters (poln. hejter) debattiert wurde. Die Herausgeber des Sammelbandes entschlossen sich auch auf eben diese Weise die wesentlichsten Stimmen in dieser Diskussion anzuordnen. Aus jedem Teil der Veröffentlichung 
Hassrede und Redefreiheit. Ein konzeptueller kulturwissenschaftlicher... 21

wollen wir die unserer Ansicht nach bedeutsamsten Forschungsansätze besprechen - wobei auf die Tatsache geachtet wird, dass die transdisziplinäre Perspektive von Haterei nicht aus den Augen verloren wird, da sie eindeutig auf die Komplexität und Vielfältigkeit der Erscheinung des Hates verweist.

\subsection{Genese und Erscheinungsräume der „Hates“}

Den Sammelband Hejterstwo - nowa praktyka kulturowa eröffnet der Beitrag Hejt - zło odwieczne czy kulturowy nowotwór? (dt. Hate - ewiges Übel oder kulturelle Neubildung) von Stanisław Stasiewicz. Der Autor skizziert den semantischen Rahmen sowie formuliert eine Definition des Internet-Hates. Der Beitrag versucht auch die Frage zu beantworten, ob Hate und Haterei gänzlich neue Erzeugnisse der modernen Kultur sind, oder aber ob sie eine neue Ausgestaltung seit Jahrhunderten existierender Praktiken sind. In dem Text werden historische Formen von Hass der Analyse unterzogen, wie beispielsweise totalitäre Propaganda, und mit deren gegenwärtigen für die Massenmedien und das Internet charakteristischen Erscheinungsformen verglichen.

Hejt internetowy jest bardzo często traktowany jako nowe zjawisko kulturowe, które w bardzo szybkim tempie zostało oswojone. Ma to wyraz nawet w spolszczeniu zapisu oryginalnego angielskiego słowa. Przyjęło się je dziś traktować jako produkt uboczny społeczeństwa ery cyfrowej, podpiętego przez dwadzieścia cztery godziny na dobę do wciąż rozrastającej się Sieci. Hejt spowszedniał na tyle, iż mimo świadomości, że każda próba skorzystania z Internetu zawiera w sobie ryzyko ekspozycji na tego typu treści, powoli zaczynamy wykształcać mechanizmy obronne. Czy jednak rzeczywiście jest to całkowicie nowy przejaw kultury? [Der Internet-Hate wird sehr oft als eine neue kulturelle Erscheinung betrachtet, die in einem äußerst raschen Tempo heimisch geworden ist. Dies kommt zum Ausdruck sogar in der Polonisierung des ursprünglich englischen Wortes. Es ist üblich geworden, es heute als ein Nebenprodukt der Gesellschaft der digitalen Ära zu betrachten, die 24 Stunden täglich an ein ständig wachsendes Netz angeschlossen ist. Der Hate ist dermaßen alltäglich geworden, dass wir, trotz des Bewusstseins, bei jedem Versuch der Internetnutzung derartigen Inhalten ausgesetzt werden zu können, langsam beginnen, Abwehrmechanismen zu entwickeln. Ist es aber tatsächlich ein gänzlich neuer Ausdruck von Kultur?] (Hejterstwo 2017: 13)³.

${ }^{3}$ Die im vorliegenden Beitrag angeführten polnischsprachigen Zitate werden jeweils einleitend im Original im ausgangssprachlichen Wortlaut beibehalten, im Anschluss folgt in Klammern das zielsprachige Pendant - Anm. des Übersetzers. 
Stasiewicz stellt im Prinzip eine rhetorische Frage, wonach er konsequent eine Reihe von Beispielen für kulturelle Praktiken aufzählt, die aus seiner Sicht das Fundament des heutigen Hates bilden:

1. Sprache der Feindseligkeit - in Opposition zu Hassrede.

2. Hassrede.

3. Mechanismen der Stigmatisierung und des Brandmarkens im Sinne von Erving Goffman.

4. Trolling.

Die Frage des verbalen Hasses greift auch Adam Olczyk auf, der ähnlich wie Stasiewicz die Frage zu beantworten versucht: Was ist Hate? In seinem Beitrag bespricht er seinen eigenen Vorschlag, wie das Wort Hate in der polnischen Sprache zu verstehen ist. Der erste Teil der Überlegungen widmet sich der Erklärung des Phänomens von Hass, mit dem Schwerpunkt auf dem Zufallscharakter dieses - wie es Olczyk ausdrückt - Gefühls (in diesem Zuge erfolgt ein direkter Bezug zum Hate). Anschließend wird der Hate mit dem Rechtsbegriff „Hassrede“ zusammengestellt, wodurch seine zwei wesentlichen Merkmale herausgearbeitet werden: (1) die Gerichtetheit auf das Individuum sowie (2) die fehlende Notwendigkeit eines ideologischen Hintergrunds.

Eine ähnliche Beobachtung finden wir bei Agnieszka Więckiewicz, die in dem Text Wobec krzywdzących stów. Kilka uwag o niezmiennych mechanizmach mowy nienawiści (dt. Angesichts verletzender Worte. Einige Bemerkungen zu unveränderlichen Mechanismen von Hassrede) - trotz der Hervorhebung einiger definitorischer Zweifel - konstatiert:

Definicja złożonego i niejednorodnego zjawiska rozumianego pod pojęciem „hejtu” jest niezwykle trudna do jednoznacznego ustalenia. Instynktownie wyczuwalna różnica między mową nienawiści, hejtem a niebezpieczną mową nie wystarczy do tego, żeby wyznaczyć twarde granice między pojęciami. Podczas gdy niebezpieczna mowa (ang. dangerous speech), obejmująca zachęcanie do podjęcia fizycznej przemocy wobec obrażanych, może zostać określona jako radykalniejsza wersja mowy nienawiści, hejt można by wstępnie określić jako „lżejszą” jej formę, która może, ale nie musi się w nią przeradzać, a także rodzaj szeroko pojętej krzywdzącej wypowiedzi, która nie wykorzystuje jednak z góry założonej ideologii, będącej czynnikiem konstytuującym mowę nienawiści [Eine eindeutige Definition der unter dem Begriff „Hate” verstandenen komplexen und uneinheitlichen Erscheinung ist äußerst schwer zu bestimmen. Der instinktiv spürbare Unterschied zwischen Hassrede, Hate und gefährlicher Rede reicht nicht aus, um harte Grenzen zwischen diesen Begriffen zu ziehen. Während gefährliche Rede (eng. dangerous speech), wel- 
che zur physischen Gewalt gegenüber den Beleidigten ermuntert, als eine radikalere Version von Hassrede bezeichnet werden kann, könnte man Hate als deren „leichtere” Form beschreiben, die sich dann in Hassrede verwandeln kann, aber nicht muss, sowie eine Art von breitgefasster verletzender Äußerung, die jedoch keine vorausgesetzte Ideologie einsetzt, die sich als konstitutives Merkmal von Hassrede versteht] (Hejterstwo 2017: 40).

In ihrem Beitrag stellt Więckiewicz der Reihe nach Argumente als Hilfsmittel bei der Unterscheidung von Hate gegenüber der Sprache der Verachtung und Hassrede vor. Aus der Perspektive verschiedener Forschungsansätze bespricht die Autorin die sozialen sowie sprachlichen Bedingtheiten des Hates. Anschließend erläutert Więckiewicz in Anlehnung an die Zusammenstellung von klassischen Texten zu Hassrede die unveränderlichen Mechanismen, die sowohl der Hassrede und der Sprache der Verachtung, als auch dem Hate zugrunde liegen.

Die Autoren des Sammelbandes Hejterstwo verweisen zugleich auf die strafrechtlichen Aspekte des Hates. Jakub Ławicki analysiert im Detail die Problematik der strafrechtlichen Verantwortlichkeit in Bezug auf die Hassrede. Der Beitrag thematisiert das Problem der öffentlichen Propagierung einer faschistischen oder einer anderen totalitären Staatsform, den Aufruf zum Hass wegen nationaler, ethnischer, rassischer, konfessioneller Unterschiede bzw. Konfessionslosigkeit, öffentlicher Beleidigung einer Bevölkerungsgruppe oder einzelner Personen aus Gründen ihrer nationalen, ethnischen, rassischen, konfessionellen Zugehörigkeit bzw. Konfessionslosigkeit. Ferner wird auf die Frage der öffentlichen und faktenwidrigen Leugnung von nationalsozialistischen, kommunistischen und sonstigen Verbrechen gegen den Frieden, gegen die Menschlichkeit oder Kriegsverbrechen gegen Personen polnischer Nationalität oder polnischen Staatsbürgern anderer Nationalitäten im Zeitraum vom 1. September 1939 bis 31. Juli 1990 eingegangen. Der Autor legt die Definition von Hassrede dar und analysiert die Merkmale der Artikel 119, 256 und 257 des polnischen Strafgesetzbuches sowie Artikel 55 des Gesetzes über das Institut des Nationalen Gedenkens ${ }^{4}$ mit Berücksichtigung der Probleme mit deren Auslegung. Abschließend verweist der Autor auf die positiven Maßnahmen seitens des Generalstaatsanwalts im Hinblick auf das Problem der Hassrede. Damit präsentiert Ławicki in seinem Beitrag ausführlich die Rechtsspezifik in Polen im Zusammenhang mit dieser leider nach wie vor aktuellen Frage.

\footnotetext{
4 Poln. Instytut Pamięci Narodowej (IPN) - Anm. des Übersetzers.
} 
Strafrechtliche Aspekte sowie die Spezifik weiterer Artikel sind jedoch ein Beispiel für einen deutlich definierten Bereich von soziokulturellen Maßnahmen. Mehrmahls entgeht der Aufmerksamkeit des Rechts das, was neuartig, fließend und in seiner Natur ausgesprochen plastisch ist. Im Fall des Hates ist es das sog. Trolling. Marcin Garbowski behauptet in seinem Beitrag Szkodniki czy „partyzanci“ cyberprzestrzeni? Próbia typologizacji trolli internetowych (dt. Schädlinge oder „Partisanen“ im Cyberspace? Versuch einer Typologisierung von Internet-Trollen):

Zastosowanie analogii do wojny i działań militarnych bynajmniej nie będzie przesadą w kontekście rozważań nad hejtem czy trollingiem. Obecnie bowiem Internet, w swojej coraz bardziej interaktywnej postaci, jest przestrzenią, w której toczy się nieustanna walka o rząd dusz. W Internecie aktywni są wielcy gracze - np. koncerny czy instytucje rządowe - którzy w świecie off-linowym dominują poprzez zawłaszczanie $\mathrm{w}$ znacznym stopniu już konwencjonalnych środków przekazu. Jednak o wiele większy wpływ na kreowanie narracji w Internecie mają mniejsi gracze, czyli blogerzy, pojedynczy użytkownicy forów internetowych, administratorzy profili czy też grup na portalach społecznościowych. Spośród tych ostatnich rekrutują się trolle Internetowe, które spontanicznie, bądź zainspirowane z zewnątrz, mogą skutecznie deprecjonować działania dużych graczy bądź wprowadzać niektórych mniejszych graczy do mainstreamu skuteczniej niż tradycyjne media. [...] Istotną cechą trollingu jako zjawiska jest to, że nie zachodzi ono bądź zwyczajnie nie ma racji bytu w kontekście prywatnym. [...] Aby zachowania trolli mogły zachodzić, potrzebny jest zatem szerszy kontekst społeczny [Der Gebrauch einer Analogie zum Krieg und Kampfhandlungen gilt im Kontext der Überlegungen zu den Phänomenen von Hate und Trolling keinesfalls als Übertreibung. Derzeit bildet das Internet in seiner immer mehr interaktiven Form einen Raum, in dem ein ununterbrochener Kampf um die Regierung der Seelen herrscht. Im Internet sind die großen Spieler aktiv - z. B. Konzerne oder staatliche Institutionen, in der Offline-Welt bereits dominant durch die massive Aneignung der konventionellen Massenmedien. Einen vielfach größeren Einfluss auf das Kreieren der Narration im Internet haben kleinere Spieler, also Blogger, individuelle Nutzer von Internetforen, Admins von Profilen oder Gruppen in sozialen Medien. Unter den letzteren werden Internet-Trolle rekrutiert, die spontan oder von außen inspiriert erfolgreich die Aktivitäten der großen Spieler herabwürdigen oder einige kleinere Spieler effizienter als traditionelle Medien in den Mainstream implementieren. [...] Eine wesentliche Eigenschaft des Trollings als einer Erscheinung ist die Tatsache, dass es in privatem Kontext entweder nicht vorkommt oder schlicht keine Existenzberechtigung hat. [...] 
Damit die Aktivität von Trollen zustande kommt, ist somit ein breiterer sozialer Kontext nötig] (Hejterstwo 2017: 69).

Um das Wesen des Problems nachzuvollziehen, schlägt der Autor die folgende Typologie der Verhaltensweisen von Trollen vor:

1) Gegenstand des Trollings:

a) Eigenwerbung;

b) ein konkretes Thema: z. B. Religion, Ideologie, Mode;

c) eine Person als Ziel: z. B. ein Prominenter, ein Politiker, eine Autorität;

d) ein institutionelles Ziel: z. B. eine politische Partei, ein konkretes Unternehmen.

2) Motivation zum Trolling:

a) psychologisch;

b) ludisch: eine mehr oder weniger sublime intellektuelle Unterhaltung, die Lust, Spaß auf Kosten der Gefühle von jemandem anderen zu empfinden oder das Auslösen intellektueller Provokation;

c) ambitioniert: die Aktivität des Trollings innerhalb einer Gemeinschaft;

d) ideologisch: resultiert aus einer starken Überzeugung von der Richtigkeit der eigenen Ansichten;

e) finanziell: finanzieller Nutzen von zum Trolling angeheuerten Personen.

\section{3) Anonymitätsniveau:}

a) vollständige Anonymität;

b) dissoziative Anonymität;

c) vorsätzliche Öffentlichkeit.

In Anlehnung an die vorhergehenden Unterscheidungen verweist Garbowski auf folgende Typen von Trollen:

1. Provokateur/Diversant: dieser Typ liegt am nächsten an der umgangssprachlichen Verwendung des Terminus „Troll“. Im Gegensatz zum Hater muss er nicht in großen Gruppen tätig sein, um zum Erfolg zu gelangen.

2. Hater: der am meisten exponierte Typ eines Trolls, somit eine Person, deren Absicht nicht darin liegt, den Disputanten oder eine Personengruppe lächerlich zu machen, sondern vielmehr zu deprimieren und nicht selten psychisch zu verletzen bzw. eine Institution anzuschwärzen. 
3. Aufmerksamkeitssucher5: eine Person, die via soziale Medien nach Aufmerksamkeit sowie Imageaufwertung der eigenen Person oder Marke strebt, wobei sie hierfür in der Regel nichtkommerzielle Kanäle einsetzt.

4. Spammer: eine eigentümliche Art des Aufmerksamkeitssuchers ist der Spammer, der nicht unbedingt auf sich selbst oder die von ihm generierten Inhalte aufmerksam machen möchte, aber auch anonym zum Zweck deren Massenverbreitung verschiedene (nicht immer adäquate) Foren ausnutzen kann.

5. Claqueur (Anti-Hater): häufig werden Claqueure insbesondere von Institutionen - Konzernen oder öffentlichen Einrichtungen - angeheuert, die ihr Image im Kontext der Glaubwürdigkeit pflegen, um damit ein Übergewicht von negativen Kommentaren auf ihren Webseiten zu vermeiden.

Bei einem derart ausgebauten Arsenal von hate-ähnlichen Kommunikationspraktiken ist die Ausarbeitung von Abwehrmechanismen nötig. So existieren in der Tat neben Gesetzbüchern auch Möglichkeiten der Bekämpfung von Hate und Trolling durch eine entsprechende Haltung, Rhetorik sowie eine Politik der Erwiderung. In ihrem Beitrag Hejtowanie hejterów, czyli jak radzimy sobie z mowa nienawiści w Internecie (dt. Das Haten von Hatern, also wie kommen wir mit Hassrede im Internet zurecht) gibt Aleksandra Wysokińska offen zu:

W ostatnim czasie jesteśmy świadkami rosnącej popularności zjawiska społeczno-kulturowego określonego mianem „hejtu”. Stał się on tematem niezwykle medialnym i nośnym, a jak wiadomo, każda akcja rodzi reakcję. Z czasem zaczęly się pojawiać inicjatyw mające na celu potępienie, napiętnowanie lub po prostu zwrócenie uwagi na problem [In letzter Zeit werden wir Zeugen einer wachsenden Popularität der soziokulturellen Erscheinung namens „Hate“. Er ist zu einem äußerst medialen und tragenden Thema geworden, und bekanntlich erzeugt jede Aktion eine Reaktion. Im Laufe der Zeit entstanden Initiativen, deren Ziel die Missbilligung, Stigmatisierung oder einfach der Verweis auf ein existierendes Problem ist] (Hejterstwo 2017: 85).

${ }^{5}$ Nach dem Wörterbuch der Polnischen Sprache bezeichnet die im Originaltext verwendete polnischsprachige Bezeichnung atencjusz eine Person, die nach ständiger Attention (Aufmerksamkeit) sucht. Als eine relativ neue Spracherscheinung wurde das Lexem für die Wahl zum polnischen Jugendwort des Jahres 2017 angemeldet, vgl. https:// sjp.pwn.pl/ciekawostki/haslo/atencjusz-atencjuszka;6383014.html (10.03.2019). Für die zielsprachige deutsche Textfassung entschloss man sich statt des englischsprachigen attention seeker für die im deutschen häufiger auftretende Bezeichnung Aufmerksamkeitssucher - Anm. des Übersetzers. 
In ihrem Artikel analysiert Wysokińska anschließend an ausgewählten Beispielen diverse Versuche von Gegenmaßnahmen gegenüber der Erscheinung der Haterei im Internet.

Auch das Referat Znany, czyli hejtowany? Czytelnicy o celebrytach na przykladzie analizy komentarzy zamieszczonych na portalu Pudelek.pl (dt. Bekannt, also gehatet? Leser über Prominente am Beispiel der Analyse von Kommentaren auf dem Portal Pudelek.pl) von Katarzyna Księżopolska (der Beitrag wurde während der Tagung präsentiert, letztendlich aber nicht in den Sammelband Hejterstwo mitaufgenommen) bildet eine exzellente Darstellung davon, auf welche Art und Weise moderne Technologien auf die interpersonalen Beziehungen eingewirkt haben, indem sie die kommunikativen Praktiken im Zeitraum der Kultur 2.0 stark beeinflussten. Księżopolska deutet darauf hin, dass es dank der computervermittelten Kommunikation (anders: CMC - computer mediated communication) $\mathrm{zu}$ einigen bedeutenden Verschiebungen im Hinblick auf solche Kategorien kam, wie etwa:

- Nichträumlichkeit: virtuelles Handeln ist nicht an einen konkreten geographischen Raum oder ein gegebenes Territorium gebunden;

- Asynchronität: die Aktivitäten im Internet werden als asynchron bezeichnet, da die Kommunikation nicht in Echtzeit stattfinden muss. Die Ausnahme bildet das Chatgespräch, das die gleichzeitige Anwesenheit der Gesprächspartner voraussetzt. Alle anderen Kommunikationsformen setzen eine gewisse Verspätung voraus;

- Nichtkörperlichkeit: in der internetvermittelten Kommunikation schiebt sich der Text in den Vordergrund, nicht etwa Kleidung, Aussehen, Nonverbales oder Körpersprache, was der Fall bei einer Kommunikation „von Angesicht zu Angesicht" ist. Zu beachten sind dabei die Emoticons als Mittel zur Belebung der Kommunikation im Internet;

- Nichtstigmatisierung: resultiert aus der vorhergenannten Eigenschaft. Das Ausschließen der Körperlichkeit und mangelnder physischer Kontakt verursachen, dass die virtuelle Kommunikation frei von Etikettierung und Stigmatisierung ist, ergo: solche Eigenschaften wie Rasse, Geschlecht oder Aussehen erscheinen nicht so relevant wie in der realen Welt;

- Anonymität: ihr liegen alle vorhergehend aufgelisteten Eigenschaften zugrunde, dank denen die netzvermittelten Interaktionen anonym verlaufen können.

Im Hinblick auf diese Aspekte der Kommunikation nennt die Autorin (nach Pyżalski 2009: 42) folgende Arten von elektronischer Aggression, unterschieden nach dem Typus des Opfers: 
Tab. 1

Arten von elektronischer Aggression nach dem Typus des Opfers

\begin{tabular}{|l|l|}
\hline Typus der elektronischen Aggression & Opfer \\
\hline $\begin{array}{l}\text { Elektronische Aggression gegenüber } \\
\text { Geschädigten }\end{array}$ & $\begin{array}{l}\text { Eine dem Täter gegenüber ,schwächere“ } \\
\text { Person, z. B. Alkoholiker oder Menschen } \\
\text { mit Behinderungen }\end{array}$ \\
\hline $\begin{array}{l}\text { Elektronische Aggression gegenüber } \\
\text { Prominenten }\end{array}$ & $\begin{array}{l}\text { Prominenter - eine berühmte Person, die } \\
\text { in den Medien auftritt (Sänger, Schauspiel- } \\
\text { er, Sportler) }\end{array}$ \\
\hline $\begin{array}{l}\text { Vorurteilsbedingte elektronische Aggres- } \\
\text { sion (bias bullying) }\end{array}$ & $\begin{array}{l}\text { Keine konkreten Individuen, aber eine } \\
\text { Personengruppe, z. B. Angehörige einer } \\
\text { bestimmten Nation, Anhänger einer Band }\end{array}$ \\
\hline $\begin{array}{l}\text { Elektronische Aggression gegenüber } \\
\text { Unbekannten }\end{array}$ & $\begin{array}{l}\text { Unbekannte Person - zufällig, oft beim } \\
\text { freien Surfen im Internet ausgesucht }\end{array}$ \\
\hline Elektronisches Mobbing & $\begin{array}{l}\text { Ein junger Mensch und Angehöriger der- } \\
\text { selben Gruppe wie der Täter }\end{array}$ \\
\hline
\end{tabular}

Quelle: Eigene Bearbeitung nach Pyżalski 2009: 42.

Księżopolska unterstreicht, das dank den dem Web 2.0 zugrundeliegenden Mechanismen die Haterei zu einer Verhaltensweise wurde, welche auf Hassrede und Aggression basiert. Der Hate, wie die Autorin hervorhebt, bezieht sich auch auf berühmte Personen, die einer ständigen Bewertung unterliegen, und kommt normalerweise zum Ausdruck in den auf sog. Klatschportalen gesetzten Kommentaren, daher präsentiert die Autorin in ihrem Beitrag die Ergebnisse ihrer Analyse von Inhalten, deren Gegenstand Kommentare auf dem polnischen Portal Pudelek.pl bilden.

\section{Literatur und Kultur versus Hate}

Kulturtexte konstruieren einerseits unsere Realität, andererseits widerspiegeln sie diese, daher findet die Erscheinung von Hate auch in diesem Bereich kultureller Praktiken zahlreiche Vertretungen. Glücklicherweise sind es meist kritische Auseinandersetzungen.

Anna Zatora konstatiert in ihrem Beitrag Kant $i$ hejterzy. O krytycyzmie literackim $i$ hejterstwie $w$ oparciu o powieść »Ciemno, prawie noc « Foanny Bator (dt. Kant und Hater. Zu literarischem Kritizismus und Haterei in Anlehnung an foanna Bators Roman »Dunkel, fast Nacht «) wie folgt: 
Od samego początku istnienia literatury i krytyki widoczne są między nimi liczne związki [...]. Obecnie można by wyodrębnić kilka rodzajów takich powinowactw: krytykę literacką, krytykę uprawianą przez pisarzy (np. w formie publicystyki), krytykę zawartą w literaturze oraz literaturę będącą krytyką. Niekiedy będą się one łączyły i nakładały na siebie nawzajem, choćby wtedy, gdy pisarz jest jednocześnie krytykiem literackim albo gdy w utworze mającym na celu zamanifestowanie postawy krytycznej wobec danego zjawiska pojawią się również elementy krytyki na poziomie fabularnym czy metakrytyka [Seit den Ursprüngen von Literatur und Kritik existieren zwischen beiden Phänomenen zahlreiche Verknüpfungen [...]. Zurzeit können mehrere Typen solcher Zusammenhänge isoliert werden: literarische Kritik, von Verfassern betriebene Kritik (z. B. in Form von Publizistik), in Literatur enthaltene Kritik sowie Literatur als Kritik. Gelegentlich werden sie sich miteinander verbinden oder überlappen, etwa im Fall, wenn der Verfasser zugleich Literaturkritiker ist oder aber wenn in einem Werk mit dem Ziel, eine kritische Haltung gegenüber einer Erscheinung zu manifestieren, ebenso auf der Ebene der Handlung kritische Elemente oder Metakritik erscheinen] (Hejterstwo 2017: 103).

Im Kontext des Romans von Joanna Bator sind für die Autorin gerade die zwei letzteren Zusammenhänge interessant: die auf der Ebene der Handlung vorkommende Kritik sowie die Kritik als eines der Hauptziele, die Aussage des Werkes. Der Beitrag beschäftigt sich mit der Frage des kritischen Potenzials eines literarischen Werkes. Die Hauptthese bildet die Behauptung von der Möglichkeit des sozialen Engagements von Literatur, nicht ohne Ausschluss der populären Literatur. In Anlehnung an die Theorie der Kritik (u. a. I. Kant, M. Foucault, R. Descartes, M. de Montaigne, M. P. Markowski) formuliert die Autorin drei Definitionen, nämlich der Kritik, des Kritizismus und der Krittelei, auf die sie sich im weiteren Teil des Beitrags bezieht. Mit Rückgriff auf den Begriff der engagierten Literatur führt die Autorin eine Analyse des Romans von Joanna Bator Ciemno, prawie noc (dt. Dunkel, fast Nacht) unter dem Gesichtspunkt der darin kritisierten Verhaltensweisen und Haltungen der Polen durch. Auf dieser Basis wird die Erscheinung der Haterei beschrieben und definiert und Bators Roman als ein auf eine bestimmte Weise engagiertes und eine soziale Mission realisierendes Werk eingestuft.

Auf ähnliche Fragen geht Edyta Janiak in ihrem Aufsatz Jeszcze krytyka czy już hejterstwo, czyli kilka słów o recepcji pisarstwa kobiecego (dt. Noch Kritik oder bereits Haterei - einige Worte zur Rezeption weiblicher Schriftsteller) ein. Ihr Beitrag bezieht sich auf die rhetorischen Kniffe und 
Metaphern, welche von Literaturkritikern in Bezug auf weibliche Schriftsteller Ende des 19. und im 20. Jahrhundert eingesetzt werden. Eine ähnliche Situation im literarischen Unterfeld in beiden genannten Zeiträumen („Invasion der weiblichen Feder“) resultierte laut Janiak in zahlreichen kritischen Rezensionen, in denen analoge stilistische Mittel isoliert werden können. Die Autorin erörtert diese Ähnlichkeiten unter anderem am Beispiel der Rezeption des Schaffens von Gabriela Zapolska im 19. Jh. sowie Izabela Filipiak und Manuela Gretkowska im 20. Jh. und stellt dabei auch die Frage nach der soziokulturellen Bedeutung des Einsatzes solcher Strategien durch die Kritiker.

Eine andere und auf gewisse Weise kreative Haltung präsentiert Jakub Musiałczyk. In dem Beitrag Co by byto, gdyby Arystofanes miat Facebooka (dt. Was wäre, wenn Aristophanes Facebook gehabt hätte) bespricht er die Komödien von Aristophanes im Hinblick auf die darin enthaltene Kritik gegenüber der politischen Machtverteilung und Demokratie in Athen, Sokrates und den Sophisten sowie Euripides und seinen Ansichten. Die Analyse bezieht sich auf die Argumente, die Sprache sowie die von Aristophanes eingesetzten Mittel (Witze, Anspielungen, Verdrehung von Eigennamen), mit denen eine negative, oft radikale Ansicht zu einem bestimmten Thema ausgedrückt wird. Dargestellt werden auch die Reaktionen der Zuschauer und der angegriffenen Griechen (Kleon und Sokrates) auf die Komödien von Aristophanes. Der Autor versucht dabei auf die Unterschiede zwischen der Kritik des antiken Komödiendichters und der heutigen Haterei hinzuweisen.

Im Gegensatz dazu präsentiert Joanna Jatczak dem Leser die neuesten literarischen Trends im Zusammenhang mit der Fandomkultur. Die Autorin von Fan wars - hejterstwo w Korei Potudniowej (dt. Fan Wars - Haterei in Südkorea) vermerkt:

Jeszcze kilkanaście lat temu w międzynarodowej świadomości Korea Południowa istniała jedynie w kontekście konfliktu z Koreą Północną. Wszystko zmieniło się za sprawą zjawiska nazywanego hallyu - koreańską falą. Mianem tym, zaproponowanym przez chińskich dziennikarzy, określa się wzrost popularności południowokoreańskiej kultury popularnej, w szczególności muzyki, telewizyjnych seriali oraz filmów. W pierwszej fazie hallyu obecne było w rejonie Azji, a dziś dotyczy całego świata. Hallyu z zainteresowania muzyką i serialami przekształciło się w popularną subkulturę, w której koreańska moda i styl idoli stały się wzorcem dla młodzieży na całym świecie. Druga faza koreańskiej fali, nazywana często hallyu 2.0, w dużej mierze opiera się na rozwoju cyfrowych technologii i mediów społecznościowych (Dal 2012: 
Hassrede und Redefreiheit. Ein konzeptueller kulturwissenschaftlicher... 31

b.s.). Fani odgrywają znaczącą rolę we współczesnej kulturze opartej bardziej na współuczestnictwie niż tylko odbiorze treści. Cechami wyróżniającymi fanów jest więc aktywność, więź z produktami kultury, funkcjonowanie w sieciach pasjonatów tych samych treści, ciągłe poszukiwanie nowych wrażeń. W przypadku hallyu podobne cechy charakteryzują zarówno fanów, jak i antyfanów, z których ta druga grupa wyraża swoje uczestnictwo i zaangażowanie zazwyczaj w postaci hejtu [Noch vor einigen Jahren existierte Südkorea im internationalen Bewusstsein einzig und allein im Kontext des Konflikts mit Nordkorea. Alles änderte sich dank dem Phänomen namens Hallyu - der koreanischen Welle. Mit diesem von chinesischen Journalisten vorgeschlagenen Ausdruck wird die steigende Popularität der südkoreanischen Popkultur bezeichnet, insbesondere von Musik, Fernsehshows und Filmen. In der ersten Phase war Hallyu im asiatischen Raum präsent, derzeit ist es ein globales Phänomen. Aus dem Interesse für Musik und Fernsehshows wandelte sich Hallyu zu einer modernen Subkultur, in der die koreanische Mode und der Stil der Idole zum weltweiten Jugendvorbild geworden waren. Die zweite Phase der koreanischen Welle, genannt Hallyu 2.0, basiert in hohem Maße auf der Entwicklung digitaler Technologien und sozialer Medien (Dal 2012: o. S.). Die Fans spielen eine bedeutsame Rolle in der modernen Kultur, die viel mehr auf der Mitwirkung als nur auf der Rezeption von Inhalten basiert. Die für Fans ausschlaggebenden Eigenschaften sind somit die Unternehmungslust, die Bindung an Kulturprodukte, die Aktivität in Netzwerken von Liebhabern derselben Inhalte, die ständige Suche nach neuen Wahrnehmungen. Im Fall von Hallyu charakterisieren dieselben Eigenschaften die Fans wie auch die Anti-Fans, die zweite Gruppe drückt ihre Beteiligung und Engagement meist in Form des Hates aus] (Hejterstwo 2017: 158).

Das Hallyu-Phänomen erweckt ein immer breiteres Interesse der Forscher, wobei sie sich vor allem allein auf die Erscheinung der wachsenden Popularität der koreanischen Kultur und deren positiven Aspekten konzentrieren. Der Beitrag von Jatczak wirft hingegen einen Blick auf die negative Seite von Hallyu. Die Autorin charakterisiert unterschiedliche Formen, welche die gegen die koreanische Welle gerichtete Haterei annimmt, sowohl im koreanischen wie internationalen Kontext. Die Haterei der Fans kann die Form physischer und psychischer Gewalt annehmen. Dank dem Internet verbreitet sich nicht nur das Hallyu, sondern auch die Haterei. Die einheimischen sowie internationalen Fans derselben Bands greifen sich gegenseitig an. Auf beiden Seiten tritt mangelndes Verständnis kultureller Unterschiede auf. Die Kämpfe zwischen den Fans sind dermaßen zugespitzt, dass Internetportale allein zum Zweck der Eskalation von Hass eingerichtet werden. Die von der Autorin angeführten Beispiele 
veranschaulichen, was für ein spannendes und erforschenswertes Thema die Erscheinung der Haterei im Zusammenhang mit dem Hallyu-Phänomen ist.

\section{Soziopolitische Kontexte}

Zurzeit wird unter anderem dank der technologischen Entwicklung das Phänomen des Hates zu einer allgegenwärtigen Erscheinung, es zu verstehen bildet wie es scheint den Schlüssel, um nicht nur einen Ausschnitt der Realität, sondern vielmehr die gesamte Gegenwart nachvollziehen zu können. Ein Aspekt dieses Phänomens ist der politische Hate. So thematisiert Kamil Durajczyk in dem Beitrag Hejterstwo w polityce - znak czasów czy odwieczny element gry politycznej? (dt. Haterei in der Politik - ein Zeichen der Zeit oder ein uraltes Element des politischen Spiels?) die Frage von Hassrede, indem er auf das weitgefasste Feld der Politik eingeht. Der Autor unterteilt die Haterei im Raum der Politik in aktiven und passiven Hate. Der erste wird durch aktiv in das politische Leben engagierte Personen, also Politiker, realisiert. Der zweite kommt durch die Aktivität der passiv zuschauenden und das politische Leben bewertenden Gesellschaft zum Ausdruck, darunter auch von Journalisten und politischen Kommentatoren. Den wesentlichen Hintergrund für die Überlegungen bildet die Frage, ob der politische Hate von je her existierte oder aber es sich dabei um ein Erzeugnis der Gegenwart handelt.

Patrycja Chrzanowska stellt hingegen die Frage nach der Rolle von Hassrede bei Erscheinungen von Diskriminierung und Stigmatisierung (poln. Titel im Original: Rola mowy nienawiści w zjawiskach dyskryminacji $i$ stygmatyzacji):

Idea i realizacja walki z krzywdzącymi i deprecjonującymi zachowaniami wobec jednostek i grup społecznych staje się wyznacznikiem kultury i rozwoju społeczeństw i ich członków. Brak społecznej zgody na dehumanizujące zachowania i działania jest jednym z gwarantów bezpiecznego i spokojnego rozwoju w sferach mikro-, mezzo- i makrospołecznej. Powszechne akty dyskryminacji są coraz rzadziej spotykane w fizycznej przestrzeni publicznej i społecznej, zwłaszcza w zachodnich społeczeństwach. We współczesnych naukowych opracowaniach „akcentuje się wzrost zrozumienia dla złożoności kwestii dyskryminacji” (Moon 2008: 1). Należy jednak zadać pytanie: czy również w niefizycznej przestrzeni, w której funkcjonuje coraz większa liczba osób, można mówić o zmniejszeniu działań dyskryminujących i wykluczających? Obserwacje przestrzeni internetowej (m.in. mediów społecznościowych, 
forów dyskusyjnych) nie dają jednoznacznej odpowiedzi. Jedynie przeprowadzenie pogłębionych, interdyscyplinarnych badań mogłoby dać wyczerpujące wyniki [Die Idee und Umsetzung der Bekämpfung von verletzenden und herabwürdigen Verhaltensweisen gegenüber einzelnen Personen und sozialen Gruppen wird zum Maßstab für Kultur und Entwicklung von Gesellschaften und deren Mitgliedern. Der Mangel an sozialer Zustimmung für dehumanisierende Verhaltensweisen und Handlungen ist einer von vielen Garanten für eine sichere und friedliche Entwicklung auf mikro-, mezzo- und makrosozialer Ebene. Öffentliche Diskriminierungsakte sind immer seltener im physischen öffentlichen und sozialen Raum vorzufinden, insbesondere in westlichen Gesellschaften. In modernen wissenschaftlichen Studien „wird das steigende Verständnis für die Komplexität der Diskriminierungsfrage unterstrichen “ (Moon 2008: 1). Man soll allerdings die Frage stellen: kann man auch im Fall des nichtphysischen Raums, in dem eine immer größere Personenzahl einen großen Teil ihres sozialen Lebens verbringt, von einer Verringerung diskriminierender und ausschließender Handlungen sprechen? Die Beobachtung des Bereichs des Internets (u. a. sozialer Medien, Diskussionsforen) bietet keine eindeutige Antwort. Nur vertiefte, interdisziplinäre Untersuchungen könnten eingehende Ergebnisse bieten] (Hejterstwo 2017: 187).

Der Beitrag von Chrzanowska betrifft die Überlegungen über die Funktion des Einsatzes von Hassrede beim Konstruieren diskriminierender und stigmatisierender Statements. Im Text werden Aussagen von Internetnutzern gezeigt, welche Feindseligkeit gegenüber anderen Nutzern des öffentlichen Raumes zum Ausdruck bringen. Den Hintergrund für die Analyse des Einsatzes von Hassrede bilden hier Quellen aus dem soziologischen und rechtswissenschaftlichen Bereich.

Auch Michał Przybylski befasst sich mit der Frage der Exklusion und Diskriminierung. In seinem Beitrag Hejterstwo: przejaw wiedzy czy niewiedzy? Analiza wypowiedzi internautów w odniesieniu do zjawiska ubóstwa (dt. Haterei: ein Anzeichen von Wissen oder Unwissen. Eine Analyse von Aussagen von Internetnutzern im Hinblick auf die Erscheinung der Armut) führt der Autor harte Fakten an:

Ubóstwo jest problemem, którego doświadczają mieszkańcy wszystkich państw niezależnie od położenia geograficznego i stopnia ich rozwoju. Według danych Eurostatu, w 2014 roku w 28 krajach Unii Europejskiej na granicy ubóstwa i ekskluzji społecznej było około 24,5\% mieszkańców krajów członkowskich. Oznacza to, że blisko 130 milionów osób żyje w warunkach zagrażających znalezieniem się na marginesie społeczeństwa. W przypadku Polski możemy mówić o około 2,8 mln osób znajdujących się w skrajnym 
ubóstwie, co oznacza realne zagrożenie dla zdrowia psychiczno-fizycznego i rozwoju człowieka (wykres 1). Z kolei poniżej granicy dochodów uprawniających do świadczeń pieniężnych z systemu pomocy społecznej znajdowało się ok. 4,5 miliona Polaków [Armut ist ein Problem, von dem die Einwohner aller Staaten, unabhängig von ihrer geographischen Lage und dem Grad ihrer Entwicklung, betroffen sind. Nach Angaben von Eurostat befanden sich im Jahr 2014 in 28 Ländern der Europäischen Union 24\% der Einwohner von Mitgliedsländern an der Armuts- und Exklusionsgrenze. Dies bedeutet, dass beinahe 130 Millionen Menschen unter solchen Bedingungen leben, dass sie von der Exklusion an den Rand der Gesellschaft bedroht sind. Im Fall Polens kann von etwa 2,8 Millionen Menschen in extremer Armut die Rede sein, was eine reale Bedrohung für die psycho-physische Gesundheit und Entwicklung eines Menschen darstellt (Abbildung 1). Unterhalb der Einkommensgrenze, welche zu finanziellen Leistungen seitens des Sozialhilfesystems berechtigt, befanden sich ca. 4,5 Millionen polnischer Bürger] (Hejterstwo 2017: 202).

Ziel des Beitrags von Przybylski ist die Analyse negativer Kommentare zu Artikeln in Bezug auf in Armut lebende Menschen, die durch Einrichtungen der Sozialhilfe unterstützt werden und finanzielle sowie nichtfinanzielle Leistungen in Anspruch nehmen. Der Autor unternimmt den Versuch, sich mit der Frage auseinanderzusetzen, ob Internetnutzer, die Hassrede gegenüber durch soziale Exklusion bedrohten Menschengruppen verwenden, dies in Anlehnung an vorhandenes Wissen in diesem Bereich tun, oder aber lediglich Stereotype gegenüber in Armut lebenden Menschen weiterverbreiten.

Thematisch verwandt sind ebenfalls die soziologischen Reflexionen von Marta Banout und Anna Pyszkowska. In ihrem Beitrag Hejtera obraz moralny: postawy wobec uchodźców w kontekście przekonań $i$ wartości (dt. Des Haters moralisches Bild: Haltungen gegenüber Flüchtlingen im Kontext der Überzeugungen und Werte) konstatieren die Autorinnen:

Kryzys migracyjny to jeden $\mathrm{z}$ tematów przewodnich ostatnich miesięcy, a dyskusje społeczne już dawno przestały opierać na faktach i wyważonych opiniach: górę wzięły emocje. Zastanawiające jest, dlaczego Polacy i ludzie w ogóle są tak podzieleni w kwestii tego, czy i w jaki sposób zaangażować się $\mathrm{w}$ pomoc uchodźcom z Syrii i krajów ościennych. Uczestnicy dyskusji, zwłaszcza toczonych w przestrzeni internetu, nie stronią od używania ostrych, nieraz wulgarnych słów w obronie własnego stanowiska. W kontekście obserwowanego zjawiska pojawia się pytanie o to, kim jest hejter, czyli osoba publikująca w Internecie pełne agresji i nietolerancji wypowiedzi. Hejterstwo, czyli mowa nienawiści, definiowane jest jako »wszelkie 
formy wypowiedzi, które szerzą, propagują czy usprawiedliwiają nienawiść rasową, ksenofobię, antysemityzm oraz inne formy nienawiści bazujące na nietolerancji, m.in.: nietolerancję wyrażającą się w agresywnym nacjonalizmie i etnocentryzmie, dyskryminację i wrogość wobec mniejszości, imigrantów i ludzi o imigranckim pochodzeniu « [Die Flüchtlingskrise ist eines der Leitthemen der letzten Monate und die öffentlichen Auseinandersetzungen werden schon längst nicht mehr auf Fakten und ausgeglichene Statements gestützt: die Oberhand gewannen die Emotionen. Es ist erstaunlich, aus welchem Grund besonders die Polen oder auch generell die Menschen dermaßen gespalten sind im Hinblick darauf, ob überhaupt und auf welche Art und Weise man sich an den Hilfsmaßnahmen für Flüchtlinge aus Syrien und dessen Nachbarländern beteiligen soll. Die Diskussionsteilnehmer, insbesondere im Fall von Internetdiskursen, verzichten keineswegs auf harsche, manchmal vulgäre Ausdrucksweise bei der Verteidigung ihrer Standpunkte. Im Kontext dieser Beobachtungen stellt sich die Frage, wer ein Hater, also eine Person, die im Internet Aussagen voller Aggression und Intoleranz veröffentlich, eigentlich ist. Haterei, also Hassrede, wird definiert als »alle Ausdrucksformen, welche Rassenhass, Xenophobie, Antisemitismus sowie andere auf Intoleranz basierende Formen von Hass weiterverbreiten, propagieren oder rechtfertigen, darunter etwa Intoleranz, die in aggressivem Nationalismus und Ethnozentrismus Ausdruck findet, Diskriminierung und Feindlichkeit gegenüber Minderheiten, Migranten sowie Personen mit Migrationshintergrund «] (Hejterstwo 2017: 216).

Ziel der Studie von Banout und Pyszkowska war die Bewertung und Analyse von Verbindungen zwischen den Haltungen der Polen gegenüber Flüchtlingen aus Syrien (neutral, positiv, negativ, hatend) in Anlehnung an die fünf Fundamente der Moral nach Jonathan Haidt (Fürsorge/ Schädigung, Gerechtigkeit/Betrug, Loyalität/Verrat, Autorität/Subversion, Heiligkeit/Degradierung) und dem empfundenen sozialen Schmerz. An der Erhebung beteiligten sich 798 Befragte, die Ergebnisse lassen kein einheitliches Erscheinungsbild von einem Hater aufstellen. In der Regel charakterisieren diesen allerdings eine starke Fremdenfeindlichkeit bei gleichzeitig starkem Loyalitätsgefühl gegenüber der eigenen Gruppe und die Anerkennung der Machtautorität.

\section{Zusammenfassung}

Wie anfangs angedeutet, konfrontieren junge Forscher ihre theoretischen Reflexionen über eine gegenwärtige kulturelle Erscheinung, ohne sich auf breitere philosophische oder anthropologische Konzeptionen zu beziehen. 
Sie verweisen auf die Eigenart der digitalen Kultur und der dort herrschenden Sitten, der Versuch einer Verallgemeinerung dieser Reflexion würde jedoch einen weit solideren Begriffsapparat erfordern. Interessant erscheint vor diesem Hintergrund auch die Auffassung der Haterei in einem breiteren Kontext der Kritik an kritischen Haltungen sowie Kritizismus und Krittelei. Wenn wir uns auf die Reflexionen von Foucault zum Projekt der Modernität auf der Basis einer ständig erneuerten kritischen Haltung beziehen wollten, dann sollten wir dieses Projekt mit den Zeiten der Aufklärung in Verbindung bringen, als auch der Begriff der Satire, Redefreiheit, aber auch der Höflichkeit und des Sentimentalismus in kritischem Kontext gesehen wurden. Eben zu jener Zeit hat sich die Überzeugung herauskristallisiert, das die Diskriminierung und Stigmatisierung von sozialen Gruppen (Frauen, Kinder, Arme, Wahnsinnige) sich nicht in Einklang mit den damals bewusst werdenden Menschen- (Thomas Paine 1791) oder Frauenrechten (Mary Wollstonecraft) bringen lässt. Dies ist auch als der Zeitpunkt der Initiierung und Fundierung des Begriffs der „politischen Korrektheit" anzusehen.

Die digitale Welt mit ihrer scheinbaren Anonymität erinnert tatsächlich an Foucaults Panopticon, in dem nicht klar ist, ob der Überwacher wirklich existiert oder nur eine Projektion unseres Eigenbewusstseins ist. Im Zeitalter von „Fake-News“ oder allgegenwärtiger „Bots“, die auch für „Hates" verantwortlich sind, fällt die Personalisierung von Aggression und Hass schwer, dagegen scheinen Stigmatisierung und Ausschließung das Hauptziel und Folge solcher Handlungen zu sein, nicht selten entwickelt von politisch reichen Sponsoren in Form von Algorithmen.

Interessant erscheinen vor diesem Hintergrund auch die Versuche der jungen Forscher zu einer terminologischen Abstufung bei der Reflexion über den „Hate“. So wie die Skala der menschlichen Emotionen die Skalarität der damit verbundenen Erscheinungen aufdeckt, suchen auch diejenigen, die über den populären „Hate" reflektieren, nach anderen unter diesem allgemeinen Begriff wie unter einem Regenschirm verdeckten skalaren Erscheinungen. Diese Herangehensweise scheint der richtige Kurs für weitere Forschungsarbeiten zu sein, um eine Erscheinung beschreiben zu können, welche höchstwahrscheinlich eine Vielzahl weiterer komplexer Phänomene in sich birgt.

Zusammenfassend lässt sich festhalten, dass aus unserem kurzen Überblick über die Reflexion über das Phänomen des Hates in Polen eindeutig hervorgeht, dass es an einem breiteren, aus der Philosophie des Menschen und der Kultur hergeleiteten interpretatorischen Rahmen fehlt. Der beste 
Beweis für diesen Mangel ist die Reflexion über die politischen Aspekte von Hate. Es ist interessant, dass das Politischsein (poln. politycznośc) in der polnischen Sprache einst mit Höflichkeit und Diplomatie assoziiert wurde (vgl. Wörterbücher der polnischen Sprache) und heutzutage häufig mit der Brutalisierung der Sprache und rücksichtslosen Wortgefechten in Verbindung gebracht wird. Dies ist eine neue Erscheinung, die möglicherweise aus der Omnipräsenz der Medien im Leben der Menschen resultiert, aber auch aus bestimmten Eigenschaften der digitalen Kultur und der Medienkonvergenz. Höflichkeit, Diplomatie und das Politischsein wurden durch Hate, Stigmatisierung und Arroganz ersetzt. Wenn man wirklich nach Habermas (2004) annimmt, dass das aufklärerische Projekt nicht überall abgeschlossen ist, so wird dies insbesondere deutlich in Kontexten rund um das Phänomen des „Hates“ - der instrumentelle Verstand in Form eines Spiels von Interessen versucht den kommunikativen Verstand mithilfe von Stigmatisierung und Eliminierung aus dem öffentlichen Raum mundtot zu machen. Anders gesagt: der egoistische Irrationalismus bekämpft die Rortyanische Rationalität, die auf der Anerkennung der Multiperspektivität des Anderen gründet.

\section{Literaturverzeichnis}

Foucault, Michel (2009): Nadzorować i karać. Narodziny więzienia (orig. Surveiller et punir. Naissance de la prison 1975). Übersetzt von Tadeusz Komendant. Warszawa.

Girard, René (1987): Kozioł ofiarny (orig. 1982). Übersetzt von Mirosława Goszczyńska. Łódź.

Habermas, Jurgen (2004): Działanie komunikacyjne i detranscendentalizacja rozumu (orig. Kommunikatives Handeln und detranszendentalisierte Vernunft, 2001). Übersetzt von Wanda Lipnik. Warszawa.

Lorenz, Konrad (1972): Tak zwane zło (orig. Das sogenannte Böse. Zur Naturgeschichte der Aggression, 1963). Warszawa.

Naruszewicz-Duchlińska, Alina (2015): Nienawiść w czasach internetu. Gdynia.

Paine, Thomas (1791): Rights of Man. Quelle: http://sqapo.com/paine.htm (01.02.2019).

Pinker, Stephen (2015): Zmierzch przemocy. Lepsza strona naszej natury (orig. The Better Angels of Our Nature: Why Violence Has Declined, 2011). Warszawa.

Pyżalski, Jacek (2009): Agresja elektroniczna wśród dzieci i młodzieży. Gdańsk.

Wollstonecraft, Mary (1792): A Vindication of the Rights of Woman. Quelle: http://sqapo.com/wollstonecraft.htm (01.02.2019). 


\title{
Quellen
}

Dynkowska, Julia/Lemann, Natalia/Wróblewski Michał/Zatora, Anna (Hg.) (2017): Hejterstwo. Nowa praktyka kulturowa? Geneza, przypadki, diagnozy. Łódź.

\section{Mowa nienawiści i wolność słowa. Konceptualna rama kulturoznawcza i antropologiczna}

\begin{abstract}
Abstrakt: Tematem artykułu jest przegląd tematyki, nurtów krytycznych i dyskursów metodologicznych u młodych badaczy zajmujących się zagadnieniem mowy nienawiści i zjawiska hejtu, które łączą się szczególnie z komunikacją w Sieci i społeczeństwem usieciowionym. Analizę przeprowadzano m.in. w oparciu o aktualne teksty zamieszczone w monografii z 2017 roku Hejterstwo - nowa praktyka kulturowa? Geneza, przypadki, diagnozy. Interpretację tendencji badawczych z obszaru nauk humanistycznych i społeczno-politycznych prezentujemy w świetle historii idei związanych z wolnością słowa.
\end{abstract}

Słowa kluczowe: mowa nienawiści, studium przypadku, kultura 2.0, perspektywa badań w Polsce.

\section{Hate Speech and Freedom of Speech. A Cultural and Anthropological Conceptual Frame}

\begin{abstract}
The article is a review of topics, critical trends and methodological discourses among young researchers dealing with the issue of hate speech and the phenomenon of hate itself, which are particularly connected with communication in the Network and the networked society. The analysis was carried out based on current texts published in the monograph from 2017 Hejterstwo - nowa praktyka kulturowa? Geneza, przypadki, diagnozy. In the paper we present the interpretation of research trends in the humanities and socio-political sciences in the light of history of ideas related to freedom of speech.
\end{abstract}

Key words: hate speech, case study, culture 2.0, research in Poland. 